\title{
mau \\ Identification and Functional Analysis of Glutathione S-Transferases from Sitophilus zeamais in Olfactory Organ
}

\author{
Daosong Xia ${ }^{1}$, Renwen Zheng ${ }^{1}$, Jianhua Huang ${ }^{2}$, Sihan Lu ${ }^{1}$ and Qingfeng Tang ${ }^{1, * \mathbb{C}}$ \\ 1 Anhui Province Key Laboratory of Integrated Pest Management on Crops, Key Laboratory of Biology and \\ Sustainable Management of Plant Diseases and Pests of Anhui Higher Education Institutes, College of Plant \\ Protection, Anhui Agricultural University, Hefei 230036, China; xiadaosong_25@163.com (D.X.); \\ zhengrenw@163.com (R.Z.); lusihan0911@163.com (S.L.) \\ 2 Institute of Insect Sciences, College of Agriculture and Biotechnology, Zhejiang University, \\ Hangzhou 310058, China; jhhuang@zju.edu.cn \\ * Correspondence: tangqf55@163.com
}

check for

updates

Citation: Xia, D.; Zheng, R.; Huang, J.; Lu, S.; Tang, Q. Identification and Functional Analysis of Glutathione

S-Transferases from Sitophilus zeamais in Olfactory Organ. Insects 2022, 13 259. https://doi.org/10.3390/ insects13030259

Academic Editor: Nickolas

G. Kavallieratos

Received: 17 November 2021

Accepted: 2 March 2022

Published: 5 March 2022

Publisher's Note: MDPI stays neutral with regard to jurisdictional claims in published maps and institutional affiliations.

Copyright: (C) 2022 by the authors. Licensee MDPI, Basel, Switzerland. This article is an open access article distributed under the terms and conditions of the Creative Commons Attribution (CC BY) license (https:// creativecommons.org/licenses/by/ $4.0 /)$
Simple Summary: Sitophilus zeamais is a worldwide pest that destroys many grain products, causing a loss of cereal quality and quantity resulting from its metabolites and behavior. Glutathione S-transferases (GSTs), as a group of odorant-degrading enzymes (ODEs), play an important role in degrading xenobiotic odorant molecules in insect olfactory sensing systems. However, there have been few reports about the function of the GST genes of S. zeamais in the odorant-degrading process. In this study, we characterized 13 full-length genes encoding GST sequences from S. zeamais and analyzed the expression pattern in different tissues of SzeaGSTd1. In addition, we investigated the ability of recombinant SzeaGSTd1 to degrade the volatile molecules of the host, and the data indicated that the content of capryl alcohol significantly decreased in the system. In summary, we believe SzeaGSTd1 plays a key role in the olfactory sensing system of S. zeamais.

\begin{abstract}
Odorant-degrading enzymes (ODEs) play an important role in rapidly degrading and inactivating odorant molecules that have completed information transmission, as well as in maintaining the stability and sensitivity of insect olfactory sensing systems. Glutathione S-transferases (GSTs), as a group of ODEs, supposedly bear the ability to catalyze the conjugation of glutathione (GSH) and xenobiotic odorant molecules in the degrading process. However, there are few reports regarding the role of the GST genes of Sitophilus zeamais in the degrading process. Thus, we characterized 13 full-length genes encoding GST sequences from S. zeamais, of which only SzeaGSTd1 contained a high abundance in the antennae. Ligand-binding assays implied that SzeaGSTd1 was able to catalyze the conjugation of GSH with 2, 4-dinitrochlorobenzene (CDNB). We investigated whether recombinant SzeaGSTd1 bears the ability to degrade the volatile molecules of the host; among the host volatiles, and found capryl alcohol to be a suitable substrate for SzeaGSTd1. These results strongly suggest that SzeaGSTd1 probably plays a role in auxiliary host location by degrading the host volatiles of capryl alcohol and exhibits a potential biological function in the olfactory sensing system of S. zeamais. Knowledge of the potential functions of SzeaGSTd1 will provide new ideas for biological control strategies for S. zeamais.
\end{abstract}

Keywords: Sitophilus zeamais; odorant-degrading enzymes; glutathione S-transferases; degradation metabolism

\section{Introduction}

Sitophilus zeamais is a worldwide pest of cereals, decreasing the quality and quantity of grain products [1-3]. The technologies used to control this insect include the use of synthetic pesticides such as phosphine [4,5], but it is now necessary to develop non-chemical control strategies for $S$. zeamais due to the global demand for decreasing pesticide residues in food and resistance to pesticides. An efficient olfactory sensing system plays a vital role in 
various insect behaviors, helping insects to locate hosts and mate and enabling smooth communication with companions [6-8]. Thus, intensive research on olfaction might help us to understand the behavioral responses of insects and identify biological targets for new control strategies in S. zeamais.

In the sensilla of insect antennae, odorant-binding proteins (OBPs) or chemosensory proteins (CSPs) can bind and transport volatile semiochemicals to odorant receptors (ORs) [9-11]. Then, the information imparted by volatile semiochemicals is recognized and insects respond with physiological behavior accordingly [12-14]. After the completion of odorant recognition and information transmission, odorants need to be degraded by a variety of odorant-degrading enzymes (ODE) to terminate the stimulation, ensuring that insects can prepare for the next odorant stimulation and respond to changes in signals $[6,15,16]$. Based on their substrate specificities, ODEs are divided into different groups, including glutathione S-transferases (GSTs), carboxylesterases (CXEs), cytochrome P450 monooxygenases (P450s), aldehyde oxidases (AOXs), and UDP-glucuronosyltransferases (UGTs) $[6,17,18]$.

In insects, GSTs are found in two categories: cytosolic and microsomal GSTs $[19,20]$. Cytosolic GSTs are divided into six classes, Delta, Epsilon, Omega, Sigma, Theta, and Zeta, of which the Delta- and Epsilon-class GSTs are insect-specific [21,22]. The high expression of GSTs in insect antennae suggests that they might be related to olfactory function in odorant degradation. Antennal-specific GST (GST-msolf1) was discovered to be located in the sex-pheromone-sensitive sensilla of Manduca sexta antennae and could modify aldehyde odorants (trans-2-hexenal), suggesting that the GST-msolf1 might be involved in olfactory system protection through inactivation of aldehyde odorants [23]. GST-pxcs1 is abundantly expressed in the chemosensory organs of Papilio xuthus, and it can inferred that GST-pxcs1 plays a role in degrading chemical ligands from the external environment [24]. Meanwhile, in some Lepidopteran species, such as Bombyx mori and Chilo suppressalis, GST genes were identified and listed as candidates for ODEs, potentially being involved in degradation of volatile odorants in the sensilla [25-27]. As the model insect for Coleoptera, Tribolium castaneuem's GSTs have already been annotated and reported [22], and TcasGSTd2 was inferred to be an olfactory-specific GST [28]. However, the functions of GSTs in degrading odorant molecules in S. zeamais have not yet been reported. Our study results will contribute to the knowledge on the function of GSTs in the olfactory sensing of S. zeamais and help us to develop new biological control strategies.

In this research, we identified 13 cytosolic GST genes from S. zeamais antennal transcriptome data. We focused our study on one Delta-class GST: SzeaGSTd1. The expression patterns in different tissues were tested, and purified recombinant SzeaGSTd1 was obtained. We investigated the enzymatic properties of recombinant SzeaGSTd1 and tested the ability of SzeaGSTd1 to interact with odorants using host volatile molecules. These results suggest that SzeaGSTd1 could degrade volatile alcohol odorants (capryl alcohol) and might function as an ODE in S. zeamais.

\section{Materials and Methods}

\subsection{Insects Reared, RNA Extraction and $c D N A$ Synthesis}

Sitophilus zeamais from the College of Plant Protection, Anhui Agricultural University, were reared on wheat grain under total darkness in glass bottles $\left(26 \pm 1{ }^{\circ} \mathrm{C}\right.$ and $80 \pm 5 \%$ relative humidity). To acquire the testing tissues, we dissected the insects into individual tissues (male antennae, female antennae, heads (without antennae), thoraces (without legs and wings), abdomens, legs, and wings).

Total RNA was isolated from cryopreserved tissues by RNAiso Plus (TaKaRa, Dalian, China) based on the manufacturer's instructions. RNA purity and concentration were tested using the NanoDrop 2000 spectrophotometer (Thermo Fisher Scientific, Waltham, MA, USA). The cDNA was synthesized from previous total RNA by a PrimeScriptTM RT reagent kit with gDNA Eraser (TaKaRa, Dalian, China) on PCR equipment (Bio-Rad S1000, Bio-Rad Laboratories, Hercules, CA, USA), with the PCR conditions based on the reagent 
instructions. Then, we stored the PCR products at $-20^{\circ} \mathrm{C}$ until the following experiments took place.

\subsection{SzeaGST Genes Identification and Sequences Analysis}

All SzeaGST sequences were obtained from our previous antennal transcriptome data on S. zeamais [29]; the sequence read archive accession number from the National Center for Biotechnology Information (NCBI) was SRX3427302. The SzeaGST sequences were identified using the BLASTX tool (https://blast.ncbi.nlm.nih.gov/Blast.cgi accessed on 22 April 2020) (E-value $<1 \times 10^{-5}$ ) at NCBI, and the sequence was then manually checked to ensure that it was a valid query $[30,31]$.

The open reading frames (ORFs) were predicted with ORF Finder (www.ncbi.nlm.nih. gov / orffinder accessed on 22 April 2020). The theoretical isoelectric points and molecular weights of the SzeaGSTs were predicted using the ExPASy server (www.expasy.org/tools/ protparam.html accessed on 22 April 2020). The phylogenetic tree with a p-distance model and the pairwise deletion of gaps [32] was constructed using MEGA 7.0, while the bootstrap support of tree branches was assessed by resampling the amino acid positions 1000 times.

\subsection{Bioinformatics Analysis of SzeaGSTd1}

The amino acid sequence alignments were produced by DNAMAN 7.0 with the default gap penalty parameters of 10 gap openings and an extension of 0.2 and then edited by GENEDOC 3.2. The secondary structure of the amino acid sequence was predicted by PSIPRED 4.0 (http:/ / bioinf.cs.ucl.ac.uk/psipred/ accessed on 22 April 2020). The web tool SWISSMODEL (https: / / swissmodel.expasy.org/ accessed on 22 April 2020) was used to predict the 3D structure. The catalytic residues of amino acids were predicted by the $C D$ search tool (https:/ / www.ncbi.nlm.nih.gov/Structure/bwrpsb /bwrpsb.cgi accessed on 22 April 2020).

\section{4. $q R T-P C R$}

On the Bio-Rad CFX96 Real-Time PCR System, cDNA samples of SzeaGSTs were tested through qRT-PCR, and endogenous reference selected the $\beta$-actin gene of $S$. zeamais. The primers (list in Table S1) were designed by Primer Premier 5. The qRT-PCR cycling parameters were set according to the manufacturer's instructions and we then measured the melting curves. As a negative control, we used sterilized $\mathrm{H}_{2} \mathrm{O}$ in the reaction mixture instead of sample cDNA. All reactions were performed in three technical replicates and three biological replicates.

The comparative $2^{-\Delta \Delta C t}$ method [33] was used to quantify the relative expression levels of SzeaGSTd1 in different tissues. Comparative expression analyses were implemented with Tukey's honestly significant difference (HSD) test $(p<0.05)$ and one-way ANOVA. We analyzed the statistical data using the Data Processing System (DPS) software [34].

\subsection{Expression and Purification of Recombinant SzeaGSTd1 Protein}

On the basis of the ORF sequence of SzeaGSTd1 (accession number of GenBank: MW390709), the specific primers (with Hind III and BamH I restriction enzyme sites) were designed (Table S1) for the ORF of SzeaGSTd1. The following conditions were employed for the PCR reaction with the TaKaRa Ex Taq ${ }^{\circledR}$ DNA Polymerase (TaKaRa, Dalian, China): $98^{\circ} \mathrm{C}$ for $30 \mathrm{~s}$, followed by 35 cycles at $98^{\circ} \mathrm{C}$ for $10 \mathrm{~s}, 55^{\circ} \mathrm{C}$ for $30 \mathrm{~s}$, and $72{ }^{\circ} \mathrm{C}$ for $1 \mathrm{~min}$, with a final extension at $72{ }^{\circ} \mathrm{C}$ for $2 \mathrm{~min}$. Here, $50 \mu \mathrm{L}$ of reaction mixture consisted of: $0.25 \mu \mathrm{L}$ of Ex Taq, $5 \mu \mathrm{L}$ of $10 \times$ Ex Taq buffer, $4 \mu \mathrm{L}$ of dNTP mixture, $2 \mu \mathrm{L}$ of cDNA, $2 \mu \mathrm{L}$ of each primer $(10 \mu \mathrm{M})$, and $34.75 \mu \mathrm{L}$ of sterilized $\mathrm{H}_{2} \mathrm{O}$. The products were inserted into pMD 19-T Vector (TaKaRa, Dalian, China) and sequenced by General Biosystems (Hefei, China).

The plasmid with the ORF of SzeaGSTd1 was digested with HamH I and Hind III and ligated into the expression vector pCold I. Then, the correct resulting pCold ISzeaGSTd1 was transformed into Escherichia coli BL21 cells (TaKaRa, Dalian, China) for expression. Bacteria were cultured in a Luria-Bertani (LB) medium (containing $50 \mu \mathrm{g} / \mathrm{mL}$ 
of ampicillin, $20 \mu \mathrm{g} / \mathrm{mL}$ of chloramphenicol, and $5 \mu \mathrm{g} / \mathrm{mL}$ of tetracycline) and grown at $37^{\circ} \mathrm{C}$ with shaking at $220 \mathrm{rpm}$ until the OD600 reached 0.4-0.5. Then, a $0.1 \mathrm{mM}$ final concentration of isopropyl $\beta$-D-thiogalactopyranoside (IPTG) was added to the medium to induce the expression of recombinant SzeaGSTd1 protein at $15^{\circ} \mathrm{C}$ with shaking at $220 \mathrm{rpm}$ for $24 \mathrm{~h}$. The bacterial cells were harvested by centrifugation at $4{ }^{\circ} \mathrm{C}$ and $12,000 \times g$ for $5 \mathrm{~min}$, then resuspended in phosphate-buffered saline (PBS, pH 7.2). At $4{ }^{\circ} \mathrm{C}$, the cells were centrifuged at $12,000 \times g$ for $20 \mathrm{~min}$ after being sonicated for $20 \mathrm{~min}$ to separate the supernatant. The recombinant SzeaGSTd1 proteins were in soluble form. Recombinant proteins were purified using $\mathrm{Ni}-\mathrm{His}$ resin and eluted using an ascending series of imidazole (10-300 mM) in balance buffer. The purified protein was dialyzed using $100 \mathrm{mM}$ of sodium phosphate buffer ( $\mathrm{pH}$ 7.2). The recombinant SzeaGSTd1 was analyzed through $12 \%$ sodium dodecyl sulfate polyacrylamide gel electrophoresis (SDS-PAGE), and the concentrations were determined using the BCA Protein Assay Kit (TaKaRa, Dalian, China).

\subsection{Enzyme Activity Assay}

The activity of SzeaGSTd1 was measured using 1-chloro-2,4-dinitrobenzene (CDNB) as the standard substrate, following the procedure adapted from Habig et al. [35]. Briefly, $4 \mu \mathrm{g}$ of recombinant SzeaGSTd1 protein was added to $100 \mathrm{mM}$ of phosphate buffer (pH 7.2 , containing a final concentration $1 \mathrm{mM}$ of GSH and different concentrations of CDNB) with a total reaction volume of $200 \mu \mathrm{L}$. Changes in absorbance at $340 \mathrm{~nm}$ (A340) at $1 \mathrm{~min}$ intervals for 5 min were monitored using Spectrophotometer 1510 (Thermo Fisher Scientific Oy, Finland). Kinetic parameters were calculated using the Michaelis-Menten plot in GraphPad Prism 5 (San Diego, CA, USA), with the data produced by the assay conditions with different concentrations of CDNB. For measuring the optimum temperature and $\mathrm{pH}$ of SzeaGSTd1, the concentrations of GSH and CDNB were fixed at $1 \mathrm{mM}$ and $2 \mathrm{mM}$, respectively. The optimum $\mathrm{pH}$ was determined in $100 \mathrm{mM}$ of PBS buffer (with a $\mathrm{pH}$ range of 5.0-9.0), and the optimum temperature was measured after preincubating recombinant SzeaGSTd1 at various temperature ranges $\left(10-60^{\circ} \mathrm{C}\right)$ for $30 \mathrm{~min}$. Based on the competition between the host volatiles and the CDNB, we added various host volatiles to an enzyme activity reaction system to measure the interaction of SzeaGSTd1 and host volatiles. We selected 10 host volatiles (Table S2) that had been reported as food-sourced volatiles of S. zeamais [36-46], and the host volatile solutions were prepared in methanol. The host volatiles (final concentration $50 \mu \mathrm{M}$ ) were preincubated with $2 \mu \mathrm{g}$ of recombinant SzeaGSTd1 for $10 \mathrm{~min}$ at $30^{\circ} \mathrm{C}$ before being added in a total volume of $200 \mu \mathrm{L}$ to the reaction system (containing a final concentration of $1 \mathrm{mM}$ of GSH and $2 \mathrm{mM}$ CDNB). Recombinant protein without the addition of host volatiles was employed as the control. The assays were conducted in at least three biological and experimental replicates.

\subsection{Metabolism Assays In Vitro}

The capability of recombinant SzeaGSTd1 to metabolize host volatiles (capryl alcohol, vanillin, and benzaldehyde) was analyzed using high-performance liquid chromatography (HPLC) on the Waters 600E equipment (Waters Corporation, Milford, MA, USA). For this purpose, the total $500 \mu \mathrm{L}$ volume reaction system containing $100 \mathrm{mM}$ of PBS (pH 7.2), $2.5 \mathrm{mM}$ of GSH, $20 \mu \mathrm{g}$ of recombinant SzeaGSTd1, and $1 \mu \mathrm{g} / \mathrm{mL}$ of vanillin or $1 \mathrm{mM}$ capryl alcohol or benzaldehyde was incubated at $30{ }^{\circ} \mathrm{C}$ with shaking at $200 \mathrm{rpm}$ for $0.5 \mathrm{~h}$; then, $500 \mu \mathrm{L}$ methanol (HPLC grade) was added to stop the reaction. Subsequently, the reaction mixture was centrifuged at $12,000 \times g$ for $20 \mathrm{~min}$, and $500 \mu \mathrm{L}$ of supernatant was filtered into HPLC vials via a $0.22 \mathrm{~mm}$ organic membrane. When the sample $(20 \mu \mathrm{L})$ was injected into a C18 column $(4.6 \times 250 \mathrm{~mm}, 5 \mu \mathrm{m}$, Waters Corporation, Milford, CT, USA), the residual content of host volatiles was analyzed with the mobile phase of $80 \%$ acetonitrile and $20 \%$ water with a $1 \mathrm{~mL} / \mathrm{min}$ flow rate at $30^{\circ} \mathrm{C}$. The absorbance wavelength for capryl alcohol was set to $206 \mathrm{~nm}$, that for vanillin was set to $230 \mathrm{~nm}$, and that for benzaldehyde set to $237 \mathrm{~nm}$. A heat-inactivated enzyme was used as the control. The experiments were performed with three replicates. 


\section{Results}

\subsection{Identification and Analysis of SzeaGSTs}

We identified 13 SzeaGST genes from the antennal transcriptome data and named them SzeaGSTd1 SzeaGSTt1. The sequence of SzeaGSTs was submitted to GenBank (MW390709MW390721), and the predicted molecular mass (MW) and theoretical pI of the protein are shown in Table 1. All SzeaGST gene sequences comprised 606 to 744 bp (all included complete ORF), encoded 116 to 239 amino acid residues, and exhibited a high identity with those of other Coleoptera insects (83.56\% to $99.17 \%$ identity match with Sitophilus oryzae and Lissorhoptrus oryzophilus) based on the result of BLASTX best hit (Table 1). For the phylogenetic analysis, 68 amino acid sequences of known insect GST genes were selected to build a phylogenetic tree with the sequences of SzeaGSTs (Figure 1), and all SzeaGSTs were clustered together into already known insect GST clades (Delta, Epsilon, Sigma, Theta, and Zeta classes).

Table 1. Summary of the GST genes identified in Sitophuls zeamais.

\begin{tabular}{|c|c|c|c|c|c|c|c|c|}
\hline Gene Name & $\begin{array}{l}\text { Length } \\
\text { (bp) }\end{array}$ & $\begin{array}{l}\text { GenBank } \\
\text { Acc. No. }\end{array}$ & $\begin{array}{c}\text { Mw } \\
(\mathrm{kDa})\end{array}$ & pI & Species & $\begin{array}{c}\text { BLASTX Best Hit } \\
\text { Acc. No. }\end{array}$ & E-Value & Identity (\%) \\
\hline SzeaGSTd1 & 744 & MW390709 & 25.55 & 6.65 & Sitophilus oryzae & XP_030752074.1 & $1 \times 10^{-151}$ & 98.23 \\
\hline SzeaGSTd2 & 666 & MW390710 & 24.04 & 4.95 & Sitophilus oryzae & XP_030764913.1 & $3 \times 10^{-159}$ & 98.64 \\
\hline SzeaGSTd3 & 651 & MW390711 & 24.38 & 5.30 & Sitophilus oryzae & XP_030767740.1 & $1 \times 10^{-146}$ & 99.17 \\
\hline SzeaGSTe1 & 645 & MW390712 & 22.56 & 5.44 & Sitophilus oryzae & XP_030753917.1 & $6 \times 10^{-153}$ & 98.13 \\
\hline SzeaGSTe2 & 657 & MW390713 & 23.97 & 7.89 & Sitophilus oryzae & XP_030753906.1 & $1 \times 10^{-157}$ & 99.08 \\
\hline SzeaGSTe3 & 678 & MW390714 & 25.31 & 4.75 & Lissorhoptrus oryzophilus & $\overline{\mathrm{AVT}} 42199.1$ & $2 \times 10^{-138}$ & 83.56 \\
\hline SzeaGSTe4 & 654 & MW390715 & 24.50 & 5.70 & Sitophilus oryzae & XP_030766193.1 & $2 \times 10^{-153}$ & 96.77 \\
\hline SzeaGSTe5 & 639 & MW390716 & 24.23 & 5.41 & Sitophilus oryzae & XP_030753847.1 & $2 \times 10^{-149}$ & 96.70 \\
\hline SzeaGSTs1 & 606 & MW390717 & 21.88 & 5.96 & Sitophilus oryzae & XP_030749148.1 & $3 \times 10^{-145}$ & 99.00 \\
\hline SzeaGSTs2 & 612 & MW390718 & 13.40 & 8.98 & Sitophilus oryzae & XP_030758386.1 & $2 \times 10^{-142}$ & 98.03 \\
\hline SzeaGSTs3 & 609 & MW390719 & 23.26 & 7.70 & Sitophilus oryzae & $\overline{A V R 54952.1}$ & $2 \times 10^{-125}$ & 85.64 \\
\hline SzeaGSTz1 & 654 & MW390720 & 18.39 & 6.37 & Sitophilus oryzae & AVR54957.1 & $2 \times 10^{-158}$ & 99.08 \\
\hline SzeaGSTt1 & 720 & MW390721 & 27.80 & 5.41 & Sitophilus oryzae & XP_030760484.1 & $2 \times 10^{-176}$ & 98.33 \\
\hline
\end{tabular}

The full-length sequence of SzeaGSTd1 is $744 \mathrm{bp}$ and encodes the proteins of 226 amino acids. The protein predicted MW is 25.55 and the pI is 6.65 (Table 1). The sequence of SzeaGSTd1 exhibits a high amino acid identity with other known insect GSTs, such as TcasGSTd2 (QES86455.1, Tribolium castaneum, 50\% identity), LdecGSTd2 (XP_023021411.1, Leptinotarsa decemlineata, 48\% identity), AtumGSTd1 (XP_019870085.1, Aethina tumida, 45\% identity), AglaGSTd1 (XP_018560761.1, Anoplophora glabripennis, 48\% identity), OtauGSTd1 (XP_022909213.1, Onthophagus taurus, 43\% identity), and OborGSTd1 (KRT81939.1, Oryctes borbonicus, $43 \%$ identity). According to the results of template matching, DmGSTd1 of Drosophila melanogaster (Protein Data Bank ID: 3mak) [47] was selected as the structural template for the SzeaGSTd1 construction model, and the sequence homology between the template and SzeaGSTd1 was 45.67\%. The GMQE structural validation (0.75) and QMEAN Z score $(-0.59)$ of the SzeaGSTd1 model showed that the quality of the SzeaGSTd1 model is very high. The structure of SzeaGSTd1 bears the typical structural characteristics of GST fold (Figure $2 A)$; the N-terminal domain has a motif topology $\left(\beta_{1}-\alpha_{1}-\beta_{2}-\alpha_{2}-\beta_{3}-\beta_{4}-\alpha_{3}\right)$, and the C-terminal domain contains five helices $\left(\alpha_{4}-\alpha_{8}\right)$, resembling a right-handed $\alpha$-helical bundle. The results of the SzeaGSTd1 sequence analysis (Figure 2B) revealed that the N-terminal domain of SzeaGSTd1 with the G site is conserved, indicating the presence of the same GSH-binding mechanism. However, the C-terminal domain with the H-site exhibits a low sequence identity, meaning that it might be responsible for the differences and diversities observed in substrate selectivity. 


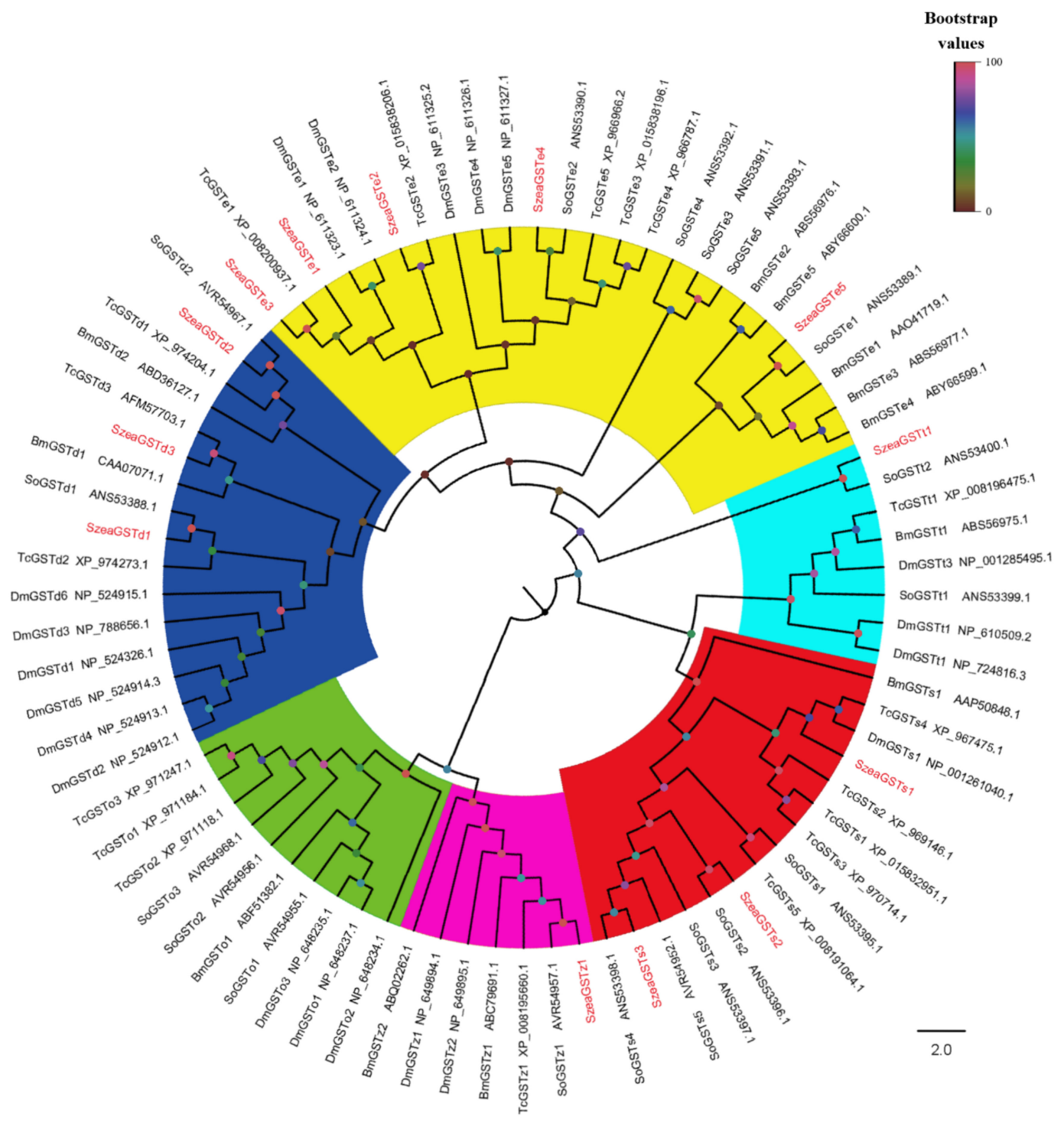

Figure 1. Phylogenetic analysis of SzeaGSTs with GSTs of other insects. The GST family is shown in different colors: blue: Delta; red: Sigma; yellow: Epsilon; green: Omega; sky blue: Theta; purple: Zeta; So: Sitophilus oryzae; Tc: Tribolium castaneum; Dm: Drosophila melanogaster; Bm: Bombyx mori.

\subsection{The Spatial Expression of SzeaGSTs}

The results of the tissue expression patterns of the SzeaGSTd1 indicated its expression in all tested tissues, but was more significantly expressed in the antennae than in other nonolfactory tissues (Figure 3). The tissue distribution of other SzeaGSTs is shown in Figure S1. SzeaGSTd2, SzeaGSTe1, SzeaGSTe4, and SzeaGSTs3 were expressed in all tissues, but the expression level measured the highest in male antennae. SzeaGSTe3 and SzeaGSTs1 were expressed predominately in the leg. SzeaGSTe2, SzeaGSTe5, and SzeaGSTz1 were expressed significantly in the wing. SzeaGSTd3 was expressed predominately in the antennae, wings, and legs. SzeaGSTs3 was expressed in all tissues, but abundantly expressed in the abdomen. SzeaGSTt1 was significantly expressed in the head. According to the results of the tissuespecific expression profiles, we chose to use SzeaGSTd1 for the functional analysis. 
A

B
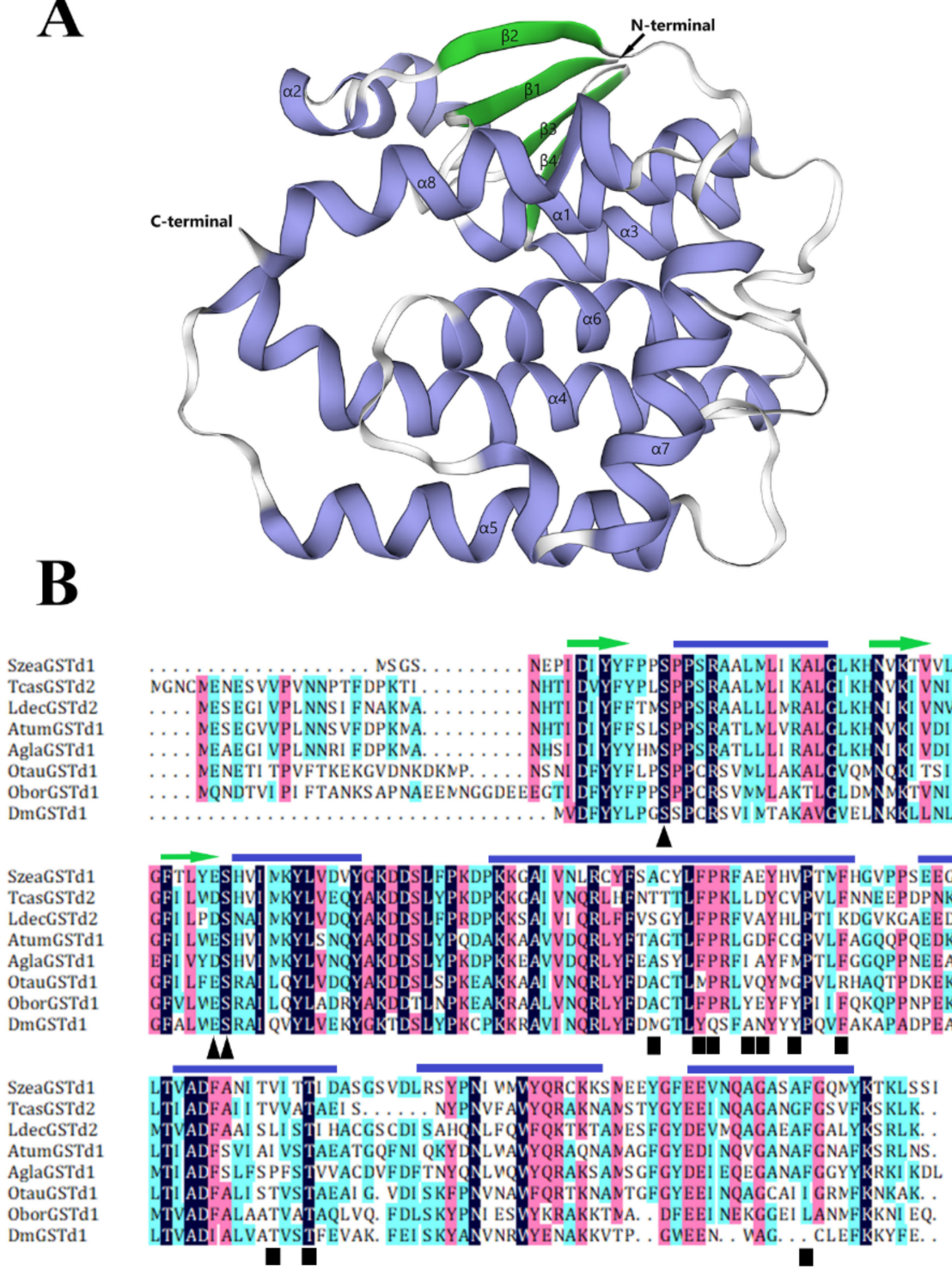

Figure 2. Amino acid sequence structure analysis of SzeaGSTd1. (A) The modeled 3D structure of SzeaGSTd1 (DmGSTd1 (Protein Data Bank ID: 3mak [47]) of D. melanogaster is the structural template). The $\alpha$-helices and $\beta$-sheets were labeled with $\alpha$ and $\beta$, respectively. (B) Sequence alignment of deltaclass GSTs from insects. Black triangles indicate amino acid residues that comprise the $G$ site and black squares indicate the amino acid residues that comprise the $\mathrm{H}$ site. The position of $\beta$-sheets ( $\beta 1-\beta 4$, indicated by the green arrow) and $\alpha$-helices ( $\alpha 1-\alpha 8$, indicated by the blue line segment) in the SzeaGSTd1 protein sequence is shown on top of the alignment. TcasGSTd2 from T. castaneum, QES86455.1; LdecGSTd2 from Leptinotarsa decemlineata, XP_023021411.1; AtumGSTd1 from Aethina tumida, XP_019870085.1; AglaGSTd1 from Anoplophora glabripennis, XP_018560761.1; OtauGSTd1 from Onthophagus taurus, XP_022909213.1; OborGSTd1 from Oryctes borbonicus, KRT81939.1; DmGSTd2 from D. melanogaster, NP_524326.1. 


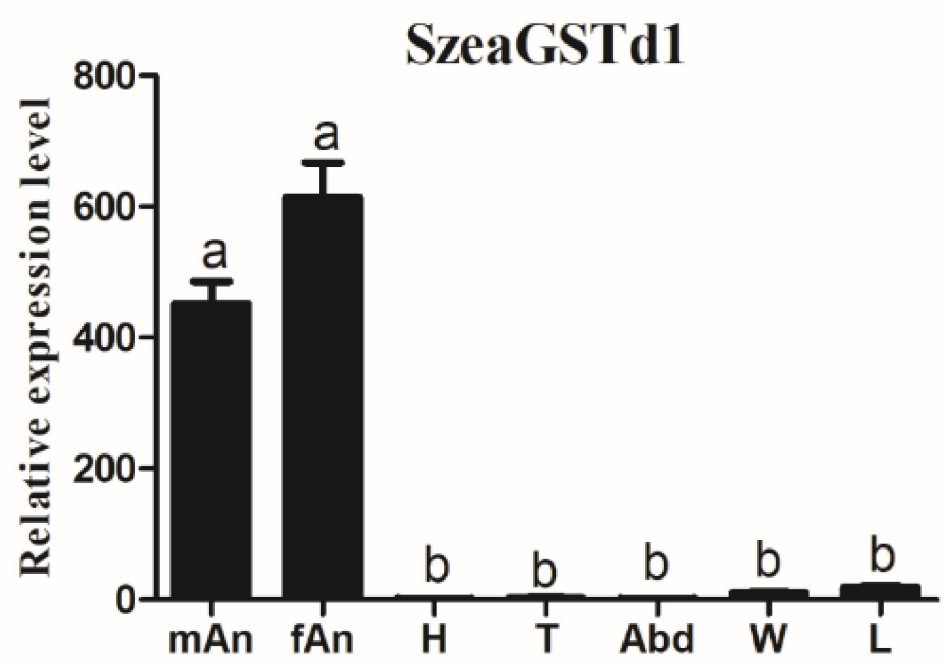

Figure 3. The relative expression levels of SzeaGSTd1 in different tissues. mAn: male antenna; fAn: female antenna; H: head; T: thorax; Abd: abdomen; W: wing; L: leg. The error bars represent the standard errors calculated from three replicates. Different letters on the error bars indicate significant differences analyzed by the ANOVA and HSD test $(p<0.05)$.

\subsection{Biochemical Characterization of Recombinant SzeaGSTd1}

In the E. coli BL21, the recombinant SzeaGSTd1 was mainly expressed as soluble protein. The expected MW of recombinant SzeaGSTd1 (containing tags of expression vector pCold I) is approximately $28 \mathrm{kDa}$, and SDS-PAGE results indicated that the SzeaGSTd1 was shown as an estimated $28 \mathrm{kDa}$ single band (Figure S2). At $\mathrm{pH} 7.5$ and $30^{\circ} \mathrm{C}$, recombinant SzeaGSTd1 exhibited optimum catalytic activity (Figure 4A,B). At the GSH concentration of $1 \mathrm{mM}$, the CDNB-conjugating activities of SzeaGSTd1 in response to different concentrations of $\mathrm{CDNB}$ were determined, and the kinetic parameter was analyzed according to the Michaelis-Menten plot (Figure 4C). The $\mathrm{V}_{\max }$ was $1047 \pm 43.09 \mu \mathrm{mol} / \mathrm{mg} / \mathrm{min}$, the $\mathrm{K}_{\mathrm{m}}$ was $0.42 \pm 0.04 \mathrm{mM}$, the catalytic number $\mathrm{K}_{\text {cat }}$ was $444.97 \mathrm{~s}^{-1}$, and the catalytic efficiency $\left(\mathrm{K}_{\text {cat }} / \mathrm{K}_{\mathrm{m}}\right)$ was $1.06 \times 10^{4} \mathrm{~s}^{-1} \mathrm{Mm}^{-1}$.

\subsection{Substrate Identification and In Vitro Metabolism with Recombinant SzeaGSTd1}

We measured the interaction of SzeaGSTd1 and host volatiles molecules using a previously described method (the competition between host volatile molecules and CDNB) of Daniel Gonzalez et al. [48]. We selected ten different host volatiles to measure the rate of inhibition of SzeaGSTd1 activity. The host volatiles were preincubated with SzeaGSTd1 for $10 \mathrm{~min}$ before being added to $1 \mathrm{mM}$ of GSH and $2 \mathrm{mM}$ of CDNB; then, the activity test was performed. The results (Figure 4D) indicate that capryl alcohol, benzaldehyde, and vanillin exhibited the strongest inhibitory effects on SzeaGSTd1 activity $(47.76 \%, 39.74 \%$, and $51.94 \%$ inhibition, respectively), among the selected host volatile molecules. The inhibition rates of these three host volatiles were significantly higher than others found, and the inhibition effects seen between 1-Hexanol, 1-Hexadecanol, Valeraldehyde, Heptaldehyde, 1-Nonanal, Decanal, and Myrcene were not significantly different. In light of this, the main function of SzeaGSTd1 might be in the metabolism of host volatile molecules.

Based on the three host volatiles of biological significance, metabolism assays of capryl alcohol, benzaldehyde, and vanillin were carried out in vitro. The results showed that the recombinant SzeaGSTd1 had the ability to degrade capryl alcohol by about $26.45 \%$ in $30 \mathrm{~min}$, but the metabolisms of benzaldehyde and vanillin were not significantly changed (Figure 5, Table S3, Figures S3 and S4). 
A

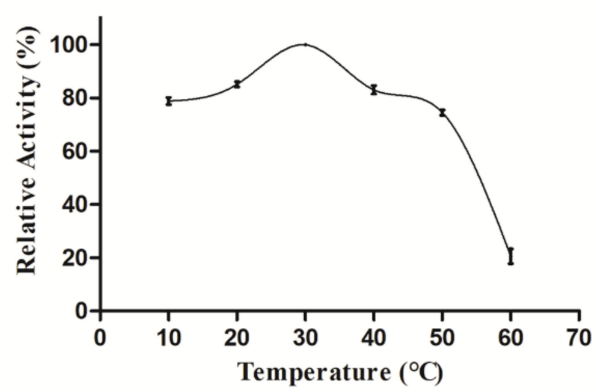

C

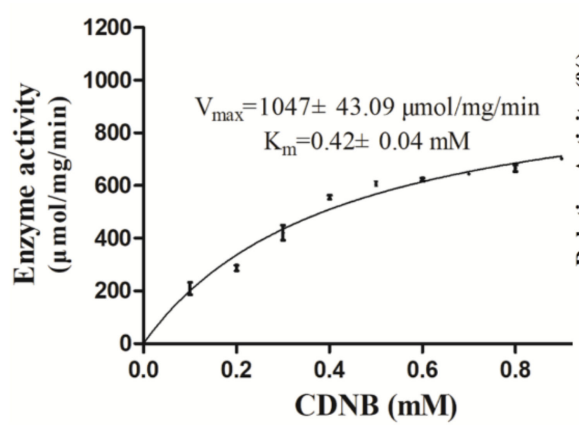

\section{B}

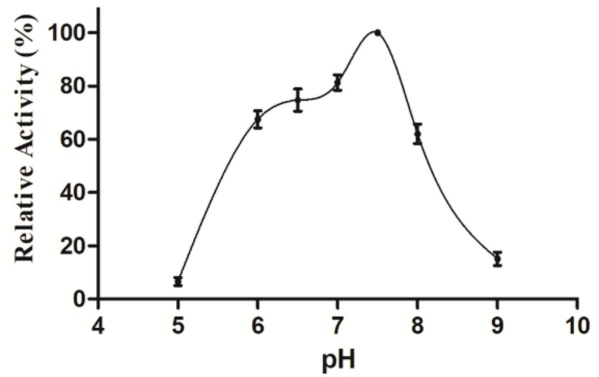

D

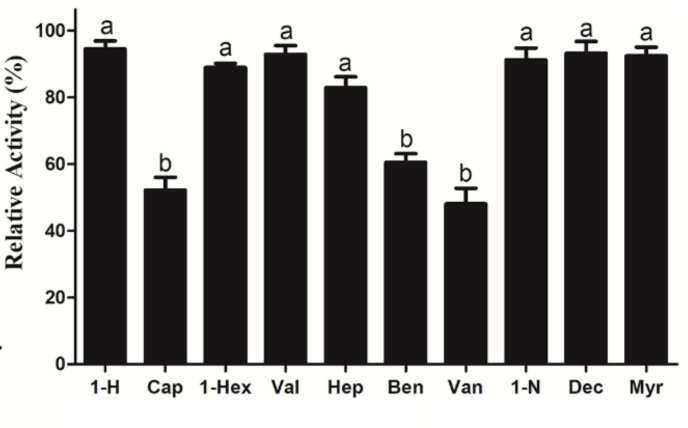

Figure 4. Enzymatic properties of recombinant SzeaGSTd1. (A) Relative activity of recombinant SzeaGSTd1 at different temperatures. (B) Relative activity of recombinant SzeaGSTd1 at different pH levels. (C) The enzyme kinetic properties of recombinant SzeaGSTd1 to CDNB. (D) Effect of host plant volatiles on recombinant SzeaGSTd1. 1-H: 1-Hexanol; Cap: capryl alcohol; 1-Hex: 1-Hexadecanol; Val: Valeraldehyde; Hep: Heptaldehyde; Ben: Benzaldehyde; Van: Vanillin; 1-N: 1-Nonanal; Dec: Decanal; Myr: Myrcene. Error bars represent mean \pm S.D. of three independent experiments conducted in three replicates. Different letters on the error bars indicate significant differences identified by ANOVA and HSD tests $(p<0.05)$.

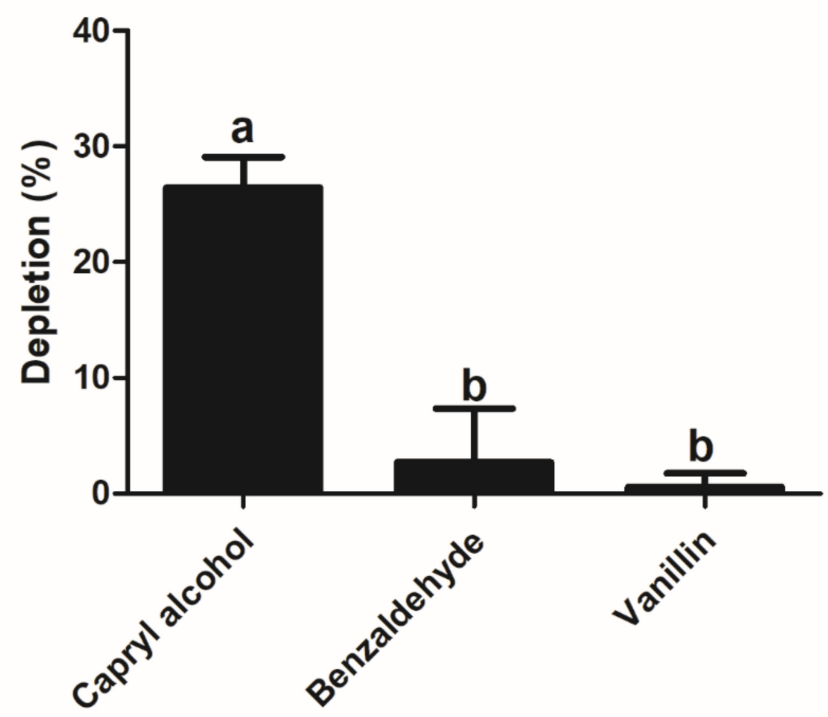

Figure 5. The degradation abilities of recombinant SzeaGSTd1 for capryl alcohol, benzaldehyde, and vanillin. Error bars represent mean \pm S.D. of three independent experiments conducted in three replicates. Different letters on the error bars indicate significant differences identified by ANOVA and HSD tests $(p<0.05)$. 


\section{Discussion}

GSTs are vital enzymes in insects which are crucial in the olfactory sensory systems of insect antennae $[21,23,49]$. Therefore, we identified 13 cytosolic GSTs from the antennal transcriptome datasets of S. zeamais (SRX3427302), including three Delta-class (SzeaGSTd1-SzeaGSTd3), five Epsilon-class (SzeaGSTe1-SzeaGSTe5), three Sigma-class (SzeaGSTs1-SzeaGSTs3), and one Theta- and Zeta-class (SzeaGSTt1 and SzeaGSTz1) GSTs. Compared to the Tribolium, the number of identified GST genes represents about one-quarter of the total, only one GST gene is specifically expressed in the antennae, and eight GST genes are significantly enriched in the antennae. The expression of the Tribolium is different in different tissues, and only TcasGSTe18 showed a high expression in the leg [28]. Our identified results are consistent with those of a previous study, in that 9 GSTs were identified in Aphidius gifuensis and Dendroctonus armandi [50,51], 12 cytosolic GSTs were identified in Cydia pomonella, and 16 GSTs were identified in the antennal transcriptome of Chilo suppressalis [25,27]. If the GSTs function in odorant degradation as the olfactory genes of insects, they will generally show preferential expression in the antennae. In the antennae of $M$. sexta, GST-msolf1 was expressed specifically and could degrade aldehyde odorants (trans-2-hexenal) [23]. The GST-pxcs1 was preferentially expressed in chemosensory organs of P. xuthus, which was inferred to degrade chemical odorants [24]. In Grapholita molesta, GmolGSTD1 was highly expressed in the antennae and could degrade (Z)-8-dodecenyl alcohol of the sex pheromone effectively, presuming that it could protect the olfactory system by acting as an ODE [52]. The antennae are an important olfactory organ and crucial in various insect behaviors due to its ability to recognize diverse chemical odorants. Thus, we selected the candidates of SzeaODEs for the expression pattern analysis, and the results showed that SzeaGSTd1 was specifically expressed in the antennae. Our results indicate that SzeaGSTd1 might play a physiological role in the olfactory sensory system of S. zeamais, but the key issues remain regarding whether SzeaGSTd1 could degrade odorants and what types of odorant could be degraded.

The principal function of GSTs is to catalyze various compounds with the conjugation of reduced GSH in order to metabolize or sequester the compounds directly. To investigate whether SzeaGSTd1 could degrade odorants, SzeaGSTd1 was expressed in vitro and purified. Then, we assayed the enzyme activity of recombinant SzeaGSTd1 by using CDNB as a substrate, and the results indicated that recombinant SzeaGSTd1 could catalyze CDNB with the conjugation of reduced GSH. When a variety of substrates in the enzyme reaction system are present, the substrate has a competitive relationship with the enzyme, and there will be a competitive inhibition relationship between the substrates, resulting in reduced enzyme activity of the substrate, which is shown by competitive inhibition in enzyme activity. Therefore, by adding odorant compounds to the enzyme activity determination system, we detected their competitive inhibition in the reaction of CDNB and GSH catalyzed by recombinant protein SzeaGSTd1 so as to verify whether the SzeaGSTd1 enzyme protein exhibits a certain binding and degradation effect on odorant compounds. In this paper, the experimental results showed that the SzeaGSTd1 enzyme protein can bind to host volatiles, and its activity to the common substrate CDNB of GST is also inhibited by volatile compounds, which indicates the presence of a competitive inhibition relationship between odorant compounds and CDNB-that is, odorant molecules "compete" for the catalytic ability of SzeaGSTd1 enzyme protein in the substrate in the reaction system. Here, we tested the ability of recombinant SzeaGSTd1 to interact with host volatile molecules. Among the ten volatile molecules, capryl alcohol, benzaldehyde, and vanillin displayed the strongest inhibitory effects on recombinant SzeaGSTd1 activity. Our data indicate that these volatile molecules exhibit a strong binding affinity with SzeaGSTd1 and suggest these as potential substrates. We used HPLC to measure whether the recombinant SzeaGSTd1 could degrade host volatile molecules in vitro, with subsequent results showing that the recombinant SzeaGSTd1 functions to selectively degrade capryl alcohol by about $26.45 \%$ in $30 \mathrm{~min}$. Previous studies have shown that capryl alcohol is a volatile component of stored grain and that the content increases significantly during the storage period $[53,54]$. 
Therefore, degradation of the residual capryl alcohol in the olfactory system of S. zeamais might contribute to locating host food and the optimum oviposition site for females.

\section{Conclusions}

In conclusion, we demonstrate that SzeaGSTd1 might play an important role in olfactory sensory system protection and alcohol odorant inactivation for S. zeamais. This promising fundamental knowledge on cereal-insect interactions may pave the way toward the development of novel insect pest management strategies.

Supplementary Materials: The following supporting information can be downloaded at: https: //www.mdpi.com/article/10.3390/insects13030259/s1, Table S1: The primers used in this study. Table S2: The host volatiles used in the substrate competitive experiment. Table S3: The degradation abilities of recombinant SzeaGSTd1 to capryl alcohol, benzaldehyde and vanillin. Figure S1: The relative expression levels of other SzeaGSTs in different tissues. Figure S2: Expression and purification of recombinant SzeaGSTd1. Figure S3: Degradation abilities of recombinant SzeaGSTd1 for capryl alcohol. Figure S4: Degradation abilities of recombinant SzeaGSTd1 for benzaldehyde and vanillin.

Author Contributions: Conceptualization, Q.T.; data curation, D.X. and Q.T.; formal analysis, D.X., R.Z., S.L. and Q.T.; funding acquisition, Q.T.; investigation, Q.T.; methodology, D.X. and Q.T.; project administration, Q.T.; validation, D.X. and Q.T.; writing—original draft, D.X.; writing—review and editing, R.Z., S.L., J.H. and Q.T. All the authors read and approved the publication. All authors have read and agreed to the published version of the manuscript.

Funding: This research was supported by the Key Program of Natural Science Foundation of the Higher Education Institutions of Anhui Province, China (grant No. KJ2019A0193); National Natural Science Foundation of China (grant No. 31500313); Key Project for University Excellent Young Talents by Anhui Province, China (grant No. gxyqZD2016035); and Key Project for Academic and Technical Leader Candidate of Anhui Province, China (grant No. 2017H107).

Institutional Review Board Statement: Not applicable.

Informed Consent Statement: Not applicable.

Data Availability Statement: Not applicable.

Conflicts of Interest: The authors declare no conflict of interest.

\section{References}

1. Adams, J.M. Weight loss caused by development of Sitophilus zeamais Motsch. in maize. J. Stored Prod. Res. 1976, 12, $269-272$. [CrossRef]

2. Abass, A.B.; Ndunguru, G.; Mamiro, P.; Alenkhe, B.; Mlingi, N.; Bekunda, M. Post-harvest food losses in a maize-based farming system of semi-arid savannah area of Tanzania. J. Stored Prod. Res. 2014, 57, 49-57. [CrossRef]

3. Keba, T.; Sori, W. Differential resistance of maize varieties to maize weevil (Sitophilus zeamais Motschulsky) (Coleoptera: Curculionidae) under laboratory conditions. J. Entomol. 2013, 10, 1-12. [CrossRef]

4. Pimentel, M.A.G.; Faroni, L.R.D.A.; Guedes, R.N.C.; Sousa, A.H.; Tótola, M.R. Phosphine resistance in Brazilian populations of Sitophilus zeamais Motschulsky (Coleoptera: Curculionidae). J. Stored Prod. Res. 2009, 45, 71-74. [CrossRef]

5. Khalid, H.; Mendonça, L.P.; Dos Santos, M.F.; Guedes, R.N.C.; Oliveira, E.E. Metabolic and behavioral mechanisms of indoxacarb resistance in Sitophilus zeamais (Coleoptera: Curculionidae). J. Econ. Entomol. 2015, 108, 362-369.

6. Leal, W.S. Odorant reception in insects: Roles of receptors, binding proteins, and degrading enzymes. Annu. Rev. Entomol. 2013, 58, 373-391. [CrossRef] [PubMed]

7. Hansson, B.S.; Stensmyr, M.C. Evolution of insect olfaction. Neuron 2011, 72, 698-711. [CrossRef]

8. Gadenne, C.; Barrozo, R.B.; Anton, S. Plasticity in insect olfaction: To smell or not to smell? Annu. Rev. Entomol. 2016, 61, 317-333. [CrossRef]

9. Steinbrecht, R.A. Odorant-binding proteins: Expression and function. Ann. N. Y. Acad. Sci. 1998, 30, 323-332. [CrossRef]

10. Vogt, R.G.; Prestwich, G.D.; Lerner, M.R. Odorant-binding-protein subfamilies associate with distinct classes of olfactory receptor neurons in insects. Dev. Neurobiol. 2010, 22, 74-84. [CrossRef]

11. Suh, E.; Bohbot, J.; Zwiebel, L.J. Peripheral olfactory signaling in insects. Curr. Opin. Insect Sci. 2014, 6, 86-92. [CrossRef]

12. Buck, L.; Axel, R. A novel multigene family may encode odorant receptors: A molecular basis for odor recognition. Cell 1991, 65, 175-187. [CrossRef] 
13. Robertson, H.M.; Warr, C.G.; Carlson, J.R. Molecular evolution of the insect chemoreceptor gene superfamily in Drosophila melanogaster. Proc. Natl. Acad. Sci. USA 2003, 100, 14537-14542. [CrossRef]

14. Mori, K.; Nagao, H.; Yoshihara, Y. The olfactory bulb: Coding and processing of odor molecule information. Science 1999, 286, 711-715. [CrossRef] [PubMed]

15. Durand, N.; Carot-Sans, G.; Bozzolan, F.; Rosell, G.; Siaussat, D.; Debernard, S.; Chertemps, T.; Maibeche-Coisne, M. Degradation of pheromone and plant volatile components by a same odorant-degradingenzyme in the cotton leafworm, Spodoptera littoralis. PLOS ONE 2011, 6, e29147. [CrossRef]

16. Ishida, Y.; Leal, W.S. Cloning of putative odorant-degrading enzyme and integumental esterase cDNAs from the wild silkmoth, Antheraea polyphemus. Insect Biochem. Mol. Biol. 2002, 32, 1775-1780. [CrossRef]

17. Huang, X.; Liu, L.; Su, X.; Fang, J. Identification of biotransformation enzymes in the antennae of codling moth Cydia pomonella. Gene 2016, 580, 73-79. [CrossRef]

18. Pelletier, J.; Bozzolan, F.; Solvar, M.; Francois, M.C.; Jacquin-Joly, E.; Maibeche-Coisne, M. Identification of candidate aldehyde oxidases from the silkworm Bombyx mori potentially involved in antennal pheromone degradation. Gene 2007, 404, 31-40. [CrossRef] [PubMed]

19. Enayati, A.A.; Ranson, H.; Hemingway, J. Insect glutathione transferases and insecticide resistance. Insect Mol. Biol. 2005, 14, 3-8 [CrossRef]

20. Jakobsson, P.J.; Morgenstern, R.; Mancini, J.; Ford-Hutchinson, A.; Persson, B. Common structural features of MAPEG-A widespread superfamily of membrane associated proteins with highly divergent functions in eicosanoid and glutathione metabolism. Prot. Sci. 1999, 8, 689-692. [CrossRef]

21. Sheehan, D.; Meade, G.; Foley, V.M.; Dowd, C.A. Structure, function and evolution of glutathione transferases: Implications for classification of nonmammalian members of an ancient enzyme superfamily. J. Biochem. 2001, 360, 1-16. [CrossRef]

22. Shi, H.; Pei, L.; Gu, S.; Zhu, S.; Wang, Y.; Zhang, Y.; Li, B. Glutathione S-transferase (GST) genes in the red flour beetle, Tribolium castaneum, and comparative analysis with five additional insects. Genomics 2012, 100, 327-335. [CrossRef] [PubMed]

23. Rogers, M.E.; Jani, M.K.; Vogt, R.G. An olfactory-specific glutathione S-transferase in the sphinx moth Manduca sexta. J. Exp. Biol. 1999, 202, 1625-1637. [CrossRef]

24. Ono, H.; Ozaki, K.; Yoshikawa, H. Identification of cytochrome P450 and glutathione-S-transferase genes preferentially expressed in chemosensory organs of the swallowtail butterfly, Papilio xuthus L. Insect Biochem. Mol. Biol. 2005, 35, 837-846. [CrossRef] [PubMed]

25. Liu, S.; Gong, Z.J.; Rao, X.J.; Li, M.Y.; Li, S.G. Identification of putative carboxylesterase and glutathione S-transferase genes from the antennae of the Chilo suppressalis (Lepidoptera: Pyralidae). J. Insect Sci. 2015, 15, 103. [CrossRef]

26. Tan, X.; Hu, X.M.; Zhong, X.W.; Chen, Q.M.; Xia, Q.Y.; Zhao, P. Antenna-specific glutathione S-transferase in male silkmoth Bombyx mori. Int. J. Mol. Sci. 2014, 15, 7429-7443. [CrossRef]

27. Huang, X.L.; Fan, D.S.; Liu, L.; Feng, J.N. Identification and characterization of glutathione S-transferase genes in the antennae of codling moth (Lepidoptera: Tortricidae). Ann. Entomol. Soc. Am. 2017, 110, 409-416. [CrossRef]

28. Dippel, S.; Kollmann, M.; Oberhofer, G.; Montino, A.; Knoll, C.; Krala, M.; Rexer, K.H.; Frank, S.; Kumpf, R.; Schachtner, J.; et al Morphological and transcriptomic analysis of a beetle chemosensory system reveals a gnathal olfactory center. BMC Biol. 2016, 14, 90. [CrossRef]

29. Tang, Q.F.; Shen, C.; Zhang, Y.; Yang, Z.P.; Han, R.R.; Wang, J. Antennal transcriptome analysis of the maize weevil Sitophilus zeamais: Identification and tissue expression profiling of candidate odorant-binding protein genes. Arch. Insect Biochem. Physiol. 2019, 101, e25142. [CrossRef]

30. Altschul, S.F.; Madden, T.L.; Schäffer, A.A.; Zhang, J.; Zhang, Z.; Miller, W.; Lipman, D.J. Gapped BLAST and PSI-BLAST: A new generation of protein database search programs. Nucleic Acids Res. 1997, 25, 3389-3402. [CrossRef]

31. Anderson, I.; Brass, A. Searching DNA databases for similarities to DNA sequences: When is a match significant? Bioinformatics 1998, 14, 349-356. [CrossRef] [PubMed]

32. Kumar, S.; Stecher, G.; Tamura, K. MEGA7: Molecular evolutionary genetics analysis version 7.0 for bigger datasets. Mol. Biol. Evol. 2016, 33, 1870-1874. [CrossRef]

33. Livak, K.J.; Schmittgen, T.D. Analysis of relative gene expression data using real-time quantitative PCR and the $2^{-\Delta \Delta C T}$ method. Methods 2001, 25, 402-408. [CrossRef] [PubMed]

34. Tang, Q.Y.; Zhang, C.X. Data Processing System (DPS) software with experimental design, statistical analysis and data mining developed for use in entomological research. Insect Sci. 2013, 20, 254-260. [CrossRef] [PubMed]

35. Habig, W.H.; Pabst, M.J.; Jakoby, W.B. Glutathione Stransferases. The first enzymatic step in mercapturic acid formation. J. Biol. Chem. 1974, 249, 7130-7139. [CrossRef]

36. Zanan, R.; Khandagale, K.; Hinge, V.; Elangovan, M.; Henry, R.J.; Nadaf, A. Characterization of fragrance in sorghum (Sorghum bicolor (L.) Moench) grain and development of a gene-based marker for selection in breeding. Mol. Breed. 2016, 36, 146. [CrossRef]

37. Chughtai, M.; Pasha, I.; Anjum, F.M.; Nasir, M.A. Characterization of sorghum and millet with special reference to fatty acid and volatile profile. Turk. J. Agric. Food Sci. Technol. 2015, 3, 515-521. [CrossRef]

38. Sansenya, S.; Hua, Y.; Chumanee, S. The correlation between 2-Acetyl-1-pyrroline content, biological compounds and molecular characterization to the aroma intensities of Thai local rice. J. Oleo Sci. 2018, 67, 893-904. [CrossRef]

39. Maga, J.A. Cereal volatiles, a review. J. Agric. Food Chem. 1978, 26, 175-178. [CrossRef] 
40. Phillips, T.W.; Jiang, X.L.; Burkholder, W.E.; Phillips, J.K.; Tran, H.Q. Behavioral responses to food volatiles by two species of stored-product coleoptera, Sitophilus oryzae (curculionidae) and Tribolium castaneum (tenebrionidae). J. Chem. Ecol. 1993, 19, 723-734. [CrossRef]

41. Concepcion, J.C. Quality evaluation, fatty acid analysis and untargeted profiling of volatiles in Cambodian rice. Food Chem. 2018, 240, 1014-1021. [CrossRef] [PubMed]

42. Salvatore, G.G.; Antonio, D.C.; Giuseppe, R. Electrophysiological and behavioral responses of Theocolax elegans (Westwood) (Hymenoptera: Pteromalidae) to Cereal Grain Volatiles. Biomed Res. Int. 2016, 2016, 5460819.

43. Cho, S.; Kays, S.J. Aroma-active compounds of wild rice (Zizania palustris L.). Food Res. Int. 2013, 54, 1463-1470. [CrossRef]

44. Toshova, T.B.; Velchev, D.I.; Subchev, M.A.; Toth, M.; Vuts, J.; Pickett, J.A.; Dewhirst, S.Y. Electrophysiological responses and field attraction of the grey corn weevil, Tanymecus (Episomecus) dilaticollis Gyllenhal (Coleoptera: Curculionidae) to synthetic plant volatiles. Chemoecology 2010, 20, 199-206. [CrossRef]

45. Balakrishnan, K.; Holighaus, G.; Weissbecker, B.; Schutz, S. Electroantennographic responses of red flour beetle Tribolium castaneum Herbst (Coleoptera: Tenebrionidae) to volatile organic compounds. J. Appl. Entomol. 2016, 141, 477-486. [CrossRef]

46. Wang, S.; Adhikari, K.; Hung, Y.C. Acceptability and preference drivers of freshly roasted peanuts. J. Food Sci. 2016, 82, 174-184. [CrossRef]

47. Wongsantichon, J.; Robinson, R.; Ketterman, A.J. Structural evidence for conformational changes of Delta class glutathione transferases after ligand binding. Arch. Biochem. Biophys. 2012, 521, 77-83. [CrossRef] [PubMed]

48. Gonzalez, D.; Fraichard, S.; Grassein, P.; Delarue, P.; Senet, P.; Nicolaï, A.; Chavanne, E.; Mucher, E.; Artur, Y.; Ferveur, J.F.; et al. Characterization of a Drosophila glutathione transferase involved in isothiocyanate detoxification. Insect Biochem. Mol. 2018, 95, 33-43. [CrossRef]

49. Xu, Z.B.; Zou, X.P.; Zhang, N.; Feng, Q.L.; Zheng, S.C. Detoxification of insecticides, allechemicals and heavy metals by glutathione S-transferase SIGSTE1 in the gut of Spodoptera litura. Insect Sci. 2015, 22, 503-511. [CrossRef]

50. Dai, L.L.; Ma, J.N.; Ma, M.Y.; Zhang, H.Q.; Shi, Q.; Zhang, R.R.; Chen, H. Characterisation of GST genes from the Chinese white pine beetle Dendroctonus armandi (Curculionidae: Scolytinae) and their response to host chemical defence. Pest Manag. Sci. 2016, 72, 816-827. [CrossRef]

51. Kang, Z.W.; Liu, F.H.; Xu, Y.Y.; Cheng, J.H.; Lin, X.L.; Jing, X.F.; Tian, H.G.; Liu, T.X. Identification of candidate odorant-degrading enzyme genes in the antennal transcriptome of Aphidius gifuensis. Entomol. Res. 2021, 51, 36-54. [CrossRef]

52. Li, G.W.; Chen, X.L.; Xu, X.L.; Wu, J.X. Degradation of sex pheromone and plant volatile components by an antennal glutathione S-transferase in the oriental fruit moth, Grapholita molesta Busck (Lepidoptera: Tortricidae). Arch. Insect Biochem. Physiol. 2018, 99, e21512. [CrossRef] [PubMed]

53. Monsoor, M.A.; Proctor, A. Volatile component analysis of commercially milled head and broken rice. J. Food Sci. 2004, 69, 632-636. [CrossRef]

54. Bryant, R.J.; Mcclung, A.M. Volatile profiles of aromatic and non-aromatic rice cultivars using SPME/GC-MS. Food Chem. 2011, 124, 501-513. [CrossRef] 